\title{
Abdominal Wall Hernias: An Epidemiological Profile and Surgical Experience from a Rural Medical College in Central India
}

\author{
Bharati Pandya, MS ${ }^{1}$ Tanweerul Huda, MS² Dilip Gupta, MS $^{3}$ Bhupendra Mehra, MS ${ }^{3}$ \\ Ravinder Narang, MS $^{3}$ \\ ${ }^{1}$ Department of General Surgery, AllMS, Bhopal, India \\ 2 Department of General Surgery, L. N. Medical College, Bhopal, India \\ ${ }^{3}$ Department of Surgery, Mahatma Gandhi Institute of Medical \\ Address for correspondence Bharati Pandya, MS, Department of \\ General Surgery, All India Institute of Medical Sciences, Bhopal, India \\ Sciences, Wardha, India \\ (e-mail: bharati_pandya@rediffmail.com).
}

Surg J 2021;7:e41-e46.

\section{Abstract \\ Keywords \\ - abdominal wall \\ - hernias \\ - hernia surgery \\ - rural setup \\ - India}

Background Abdominal wall hernia is a common surgical entity worldwide with groin hernias having the most common presentation among them. They are a cause of morbidity and mortality if not addressed in time. A variety of surgical methods are available for the repair of hernias. The tension-free repair using synthetic mesh has the least recurrence and is the most accepted.

Aim To describe the surgical burden and clinical profile of abdominal wall hernias as well as experiences in their management in a rural setup.

Methods This was a retrospective observational study of all the cases of abdominal wall hernias presenting to various surgical divisions of Mahatma Gandhi Institute of Medical Sciences, Sevagram, during a two-year period from December 2011 to November 2013. Relevant details were collected from the hospital information statistics and patient file records and analysis of obtained data was done.

Result A total of 910 out of 90,056 surgical outpatients (10.10\%) seen during this period had abdominal wall hernias; 816 (89.67\%) got operated. A total of $163(20 \%)$ of 816 were operated in an emergency. Groin hernias were the most common 653 (80\%), followed by incisional $82(10 \%)$, umbilical and paraumbilical 41 (5\%), epigastric $33(4 \%)$, and rarer hernias in $8(1 \%)$. Of 816 operations, $24(2.9 \%)$ had recurrent hernias and 83 $(10.17 \%)$ were pediatric patients. Male to female ratio was $9: 1$ in adults and $4: 1$ in children. The median age among adults was 49 years (range: $14-95$ years), and among the pediatric age group, it was 7 years (range: 3 months- 14 years). The majority of the adult patients were from a low-income group and presented more than 2 years after symptoms appeared. Comorbid conditions encountered were hypertension in 212 (26\%), diabetes in 155 (19\%), chronic airway disorders in $449(55 \%)$, cardiac problems in $163(20 \%)$, obesity in $10(1.2 \%)$, and chronic renal failure and liver disorder in $82(1 \%)$. Predisposing factors in the majority of the patients were chronic cough 449 (55\%), prostatic problems in 187 (23\%), chronic constipation in $163(20 \%)$, previous surgeries in $82(10 \%)$, obesity in $10(1.2 \%)$, and ascites in $9(0.1 \%)$. Hernia surgery was performed received

April 4, 2020

accepted after revision

November 12, 2020
DOI https://doi.org/

$10.1055 / \mathrm{s}-0040-1722744$.

ISSN 2378-5128. (c) 2021. The Author(s).

This is an open access article published by Thieme under the terms of the Creative Commons Attribution License, permitting unrestricted use, distribution, and reproduction so long as the original work is properly cited. (https://creativecommons.org/licenses/by/4.0/)

Thieme Medical Publishers, Inc., 333 Seventh Avenue, 18th Floor, New York, NY 10001, USA 
laparoscopically in 51 (6.25\%) patients. Simultaneous other surgeries were performed in $130(16 \%)$ patients. Mortality occurred in $2(0.24 \%)$ patients operated in emergency, and chief morbidity was due to wound infection in $25(3 \%)$ and chronic pain in $30(3.9 \%)$ patients.

Conclusion Abdominal wall hernias are common clinical entities. Although the pattern of presentation and management is similar, the challenges faced in a rural setup are due to ignorance, social inhibitions, and financial restraints, leading to delayed presentations which increase their morbidity and mortality. Health programs and surveys to increase awareness in rural areas as well as cutting down on expenses could help these patients.

An abdominal wall hernia is an abnormal protrusion of a peritoneal-lined sac through the musculo-aponeurotic covering of the abdomen. ${ }^{1}$ The most common variety is groin hernias, of which inguinal hernias (direct and indirect) are far more common than femoral hernias. Hernias of the abdominal wall are quite common, having a prevalence of $1.7 \%$ for all ages and $4 \%$ for those older than 45 years. ${ }^{2}$ Hernias of the inguinal region account for $75 \%$ of abdominal wall hernias, with a lifetime chance of $27 \%$ in males and $3 \%$ in females. ${ }^{2}$ More than 20 million hernias are estimated to be repaired all over the world every year. The other varieties are umbilical, paraumbilical, epigastric, incisional, and rarer ones like Spigelian and traumatic hernias. The inguinal hernia has a male preponderance, while femoral hernias are more common in females. Common in the pediatric age group is indirect inguinal and umbilical hernias. Symptomatology is usually suggestive, and clinical examination is the mainstay of diagnosis. However, some hernias may need radioimaging for diagnosis. Mesh repair is the preferred method of repair due to decreased recurrence rates, but herniorrhaphy is a cost-effective method of choice for many patients. Herniotomy and Mayo's repair are the procedures of choice in pediatric patients. Laparoscopic surgery has become more common due to low postoperative morbidity and early return to work but is not very cost-effective in rural setups.

The problem with developing countries, especially in their rural population, is medical ignorance, cost restraints, and social inhibitions. Delayed presentations add to postoperative morbidity and mortality. The aims are to train the residents in surgical units and to perform the most cost-effective surgeries with minimum morbidity, ensuring early return to work for these patients. Simultaneous efforts are required to conduct area-wise surveys, educating the masses, and cutting down on expenses, thereby making an early diagnosis and providing the best techniques available to these strata of society.

Our aims in this study were to assess the clinical burden and profile of hernia patients in a rural medical college and to describe our experience in managing them.

\section{Methodology}

This rural district has an area of approximately $6,310 \mathrm{~km}^{2}$ and a population of around 15 lakhs with Asian ethnicity. As much as $76 \%$ of the total population is rural, with $42 \%$ of the population living below the poverty line. There are only two teaching medical college hospitals (tertiary care centers) serving this area. This was a retrospective study conducted at our rural medical college at Mahatma Gandhi Institute of Medical Sciences, which is a tertiary medical care center situated in the central part of India. It is a trust-run hospital with aid being received from the government. It is based on self-paying with minimum charges due to government and state funding.

All the patients of external abdominal wall hernias who attended the different surgical sections from December 1, 2011, to December 1, 2013, were included in the study. A proforma was designed and relevant details were collected from the hospital information statistics and clinical records of the patients seen during these 2 years. Surgery is performed by general surgeons along with surgical officers who are also well-versed in laparoscopic surgeries. Due to a lack of pediatric surgeons at this setup, the pediatric hernias are also managed by general surgeons. Data included the sociodemographic information, presentation details, comorbid conditions, choice of anesthesia and surgical procedures along with their outcomes and follow-up details,

The obtained data were analyzed using frequency distribution, percentages, range, mean, tables, and charts to obtain the results. Statistical tests were performed to relate the relevance as was felt necessary.

\section{Results}

The study was performed by retrospective analysis of data on all anterior abdominal wall hernias in our hospital, a tertiary care hospital with an attached medical college in a rural setup, which is the first of its kind in the country.

The total surgical outpatient attendance during this period of two years was of 90,056. A total of 910 (10.10\%) of these patients had anterior abdominal wall hernias. A total of 816 patients presented themselves for surgery. Groin hernias accounted for $80 \%$ of the lot, while incisional hernias (10\%), umbilical/paraumbilical (5\%), epigastric (4\%), and rare hernias (1\%) mad up the rest (-Fig. 1 ).

The male (728) to female (88) ratio was 9:1 in adults and $4: 1$ (67:16) in children. The median age among adults was 49 years (range: $14-95$ years), and among the pediatric age group, it was 7 years (range: 3 months-14 years) (-Fig. 2). 


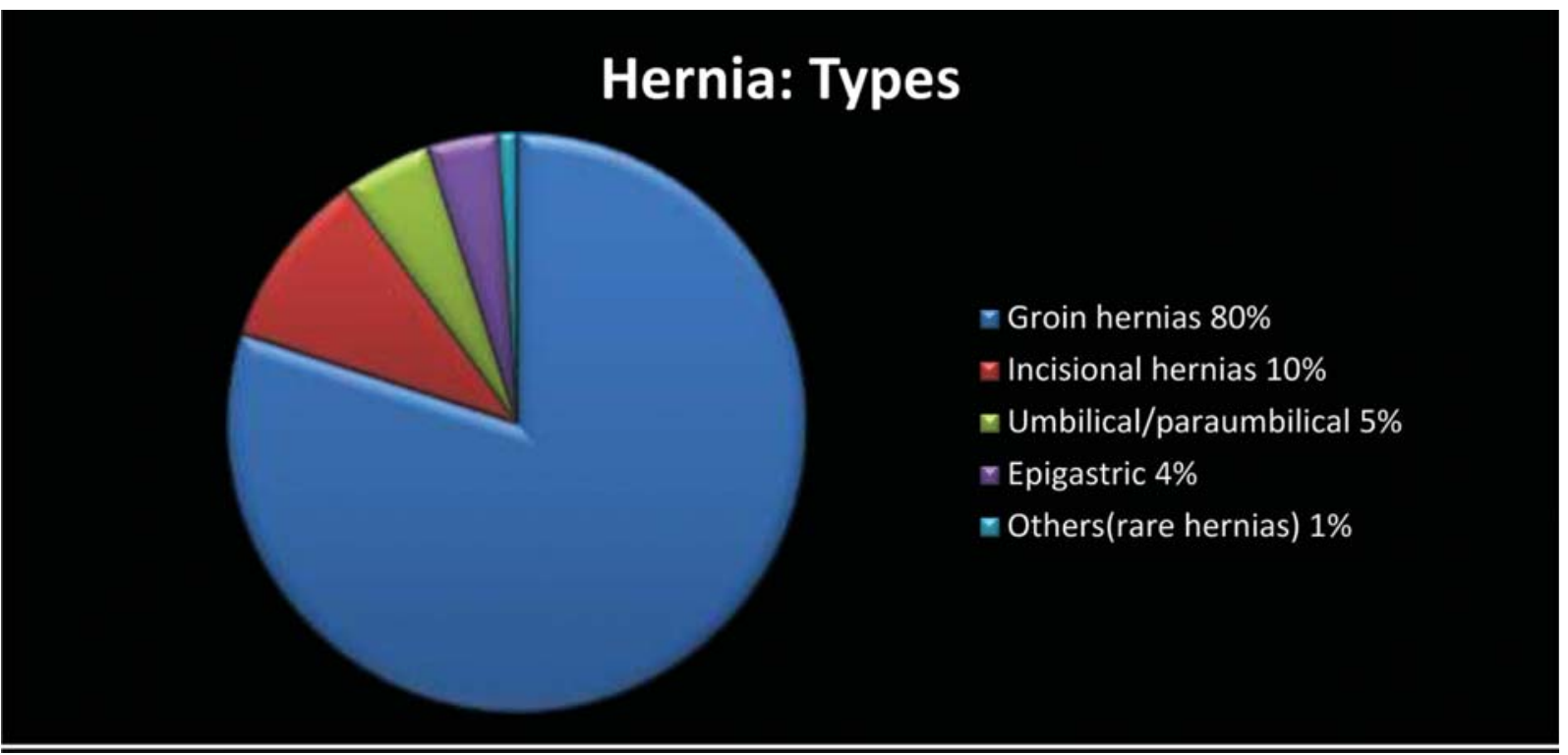

Fig. 1 Different types of hernias.

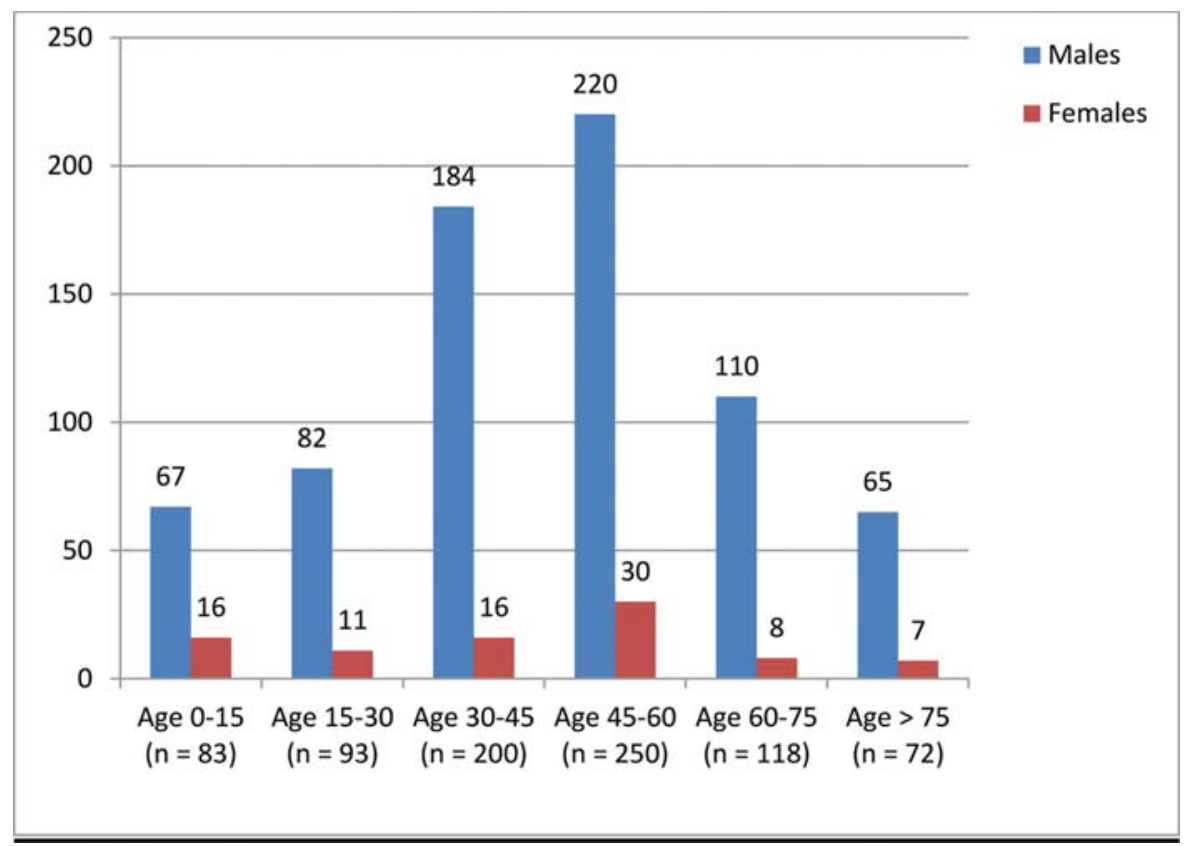

Fig. 2 Age-wise frequency of presentation.

Predisposing factors in a majority of the patients were chronic cough 449 (55\%), prostatic problems in 187 (23\%), chronic constipation in 163 (20\%), previous surgeries in 82 (10\%), obesity in 10 (1.2\%), and ascites in $9(1.1 \%)$ (- Table 1). In females, additional factors of multiparity in $50(6.1 \%)$ and transabdominal gynecological surgeries in 32 (4.0\%) patients were observed. In pediatric and young adults, the preperitoneal sac in 79 (89\%), excessive crying and weak musculature attributed to 21 (25\%), and chronic respiratory infections in 19 (23\%) were the predisposing factors discernable.

Comorbid conditions encountered were hypertension in 212 (26\%), diabetes in 155 (19\%), chronic airway disorders in 449 (55\%) cardiac problems in 163 (20\%), obesity in $10(1.2 \%)$, chronic renal failure in $3(0.36 \%)$, and liver disorder in 5 (0.61\%) (-Table 1).
Of 816 operations, 24 (2.9\%) had recurrent hernias and 83 (10.17\%) were pediatric patients, mostly congenital inguinal and epigastric. Most of our study patients had normal build and only $10(1.2 \%)$ cases of obesity were recorded. The bilateral hernia was seen only in 56 (6.56\%) patients. As much as $73 \%$ of the hernias were acquired, of which $74 \%$ were incomplete and approximately $84 \%$ were indirect. Cough impulse and reducibility were seen in approximately $75 \%$ of the patients with hernias.

Surgeries performed were subject to the type of hernia. Open Lichtenstein's repair was performed in the majority of inguinal hernias, followed by Bassini's repair. Open Meshplasty or Lap Meshplasty was the surgery of choice for umbilical, epigastric, incisional, and recurrent hernias, depending on the affordability of the patient. Pediatric inguinal hernias 
Table 1 Predisposing factors and co-morbid conditions

\begin{tabular}{|l|l|l|l|l|}
\hline $\begin{array}{l}\text { I. Predisposing } \\
\text { Factors }\end{array}$ & $\begin{array}{l}\text { Male } \\
\mathbf{( 7 2 8 )}\end{array}$ & $\begin{array}{l}\text { Female } \\
\mathbf{( 8 8 )}\end{array}$ & $\begin{array}{l}\text { Total } \\
(\mathbf{n}=\mathbf{8 1 6})\end{array}$ & \%age \\
\hline $\begin{array}{l}\text { Excessive crying } \\
\text { (in children) }\end{array}$ & 17 & 4 & $21 / 83$ & 25 \\
\hline $\begin{array}{l}\text { Chronic resp. } \\
\text { infections } \\
\text { (in children) }\end{array}$ & 15 & 4 & $19 / 83$ & 23 \\
\hline Pre-peritoneal sac & 203 & 15 & 218 & 26.7 \\
\hline Strenuous exercises & 80 & 2 & 82 & 10 \\
\hline $\begin{array}{l}\text { Chronic cough/ } \\
\text { smoking }\end{array}$ & 400 & 49 & 449 & 55 \\
\hline $\begin{array}{l}\text { Bladder outlet } \\
\text { obstruction }\end{array}$ & 186 & 2 & 188 & 23 \\
\hline $\begin{array}{l}\text { Chronic } \\
\text { constipation }\end{array}$ & 81 & 82 & 163 & 20 \\
\hline Previous surgeries & 48 & 34 & 82 & 10 \\
\hline Obesity & 2 & 8 & 10 & 1.2 \\
\hline Ascites & 3 & 6 & 9 & 1.1 \\
\hline Multiparity & 0 & 50 & 50 & 6.1 \\
\hline Il. Comorbidity & Male & Female & $\mathbf{n = 8 1 6}$ & $\%$ age \\
\hline Hypertension & 152 & 60 & 212 & 26 \\
\hline Diabetes & 85 & 70 & 155 & 19 \\
\hline $\begin{array}{l}\text { Chronic airway } \\
\text { disorders }\end{array}$ & 400 & 49 & 449 & 55 \\
\hline Cardiac problems & 108 & 55 & 163 & 20 \\
\hline Obesity & 4 & 6 & 10 & 1.2 \\
\hline $\begin{array}{l}\text { Chronic renal } \\
\text { disorders }\end{array}$ & 2 & 1 & 3 & 0.36 \\
\hline $\begin{array}{l}\text { Chronic liver } \\
\text { disorders }\end{array}$ & 4 & 1 & 5 & 0.61 \\
\hline
\end{tabular}

underwent herniotomy. Pediatric and few adult hernias were repaired with Mayo's procedure. Mesh was avoided in children. Laparoscopic surgery was performed in only 51 (6.25\%) patients (-Table 2).

Morbidity was mainly due to wound infection in 20 (2.4\%). Long-term morbidity was due to chronic pain in 20 (2.4\%) patients. Recurrence was documented only in $6(0.7 \%)$ cases who reported back within a year (-Table 2). The exact figures could not be quoted as long-term follow-up was not feasible.

A total of 163 (20\%) patients were operated in emergency and had presented with irreducibility and pain. Strangulation was present in $5(0.61 \%)$ patients requiring resection anastomosis. Mortality occurred in $2(0.24 \%)$ patients operated in an emergency; one had a perforation of a gangrenous segment in the scrotum, presenting very late with Fournier's gangrene, and the second, who had cirrhosis with a strangulated umbilical hernia and skin excoriations, succumbed postoperatively.

Other surgeries were performed simultaneously in 130 (16\%) patients, with the most common being opposite side hernia (-Table 3 ).

\section{Discussion}

This retrospective, observational study was done to look for the various etiological factors and clinical presentations of different varieties of abdominal wall hernia. It was also a complete profile study to learn the effect of various comorbidities, surgical options, and outcomes feasible in a rural setup. The study is from a tertiary care center located in rural India which has also begun with laparoscopic procedures for hernial repair.

In infants, hernias are attributed to preformed sacs, and it has been said that inguinal hernia is a disease of infants due to defect in the inguinal canal by some, while others have found a higher incidence of inguinal hernia in higher age groups. Our study demonstrated that inguinal hernia was seen with an increase in age but equally true is that there were many pediatric patients with congenital inguinal hernia also. Literature quotes the mean age of inguinal hernia to be 40 to 60 years. ${ }^{3}$ Our experience was similar, and this age group leads to an economic burden on account of the productive age group being affected. In all age groups, males were more affected. Literature quotes a ratio of 20:1 in males as compared with females. However, femoral hernias, epigastric hernias, and incisional hernias are more common in females, who delay their presentation due to a variety of reasons. In the Indian rural population, the main reasons are their family responsibilities and inability to approach hospital care due to social inhibitions, fear of operative intervention, and the tendency to conceal their medical issues. Factors responsible in males are strenuous activities, chronic cough, and preformed sacs. ${ }^{3-5}$ Even males tend to present late due to their fear of surgery and loss at work, causing financial burden on the family. These factors were comparable to other developing countries. ${ }^{6-8}$

The most common surgical procedure opted for was Lichtenstein's mesh repair technique, which is the simplest and has the advantage of being an open, tension-free repair with the least rates of recurrence. ${ }^{3,9,10}$ For children, the choice was herniotomy with minimal postoperative complications. We performed laparoscopic repairs in 51 (6.25\%) patients at our setup. The reason behind this choice is an early return to work, faster recovery, and decreased morbidities like nerve entrapment. The cost of the procedure was a cause of restraint in our patients; also, the time taken is more for laparoscopic procedures as compared with open and it matters, as the resultant time of anesthesia and affection of the time management of operating theater happens to be a major concern.

In our observational study, the complication rates were $8.0 \%$, which is relatively less compared with $4.2 \%$ to as high as $12.4 \%$ as quoted by other series in the literature. ${ }^{8}$ Our study had $86.8 \%$ of cases performed electively as compared with $61.5 \%$ cases in other series, and this could have been a probable factor for low complications. ${ }^{8}$ Emergency surgeries performed on complicated hernias led to the mortality quoted, due to perforation and strangulation of the incarcerated bowel loop, thus proving the fact that neglect and late presentation results in dismal outcomes. The coexistent morbidities also add to the overall morbidity, as patients develop respiratory and cardiac complications that are difficult to manage postoperatively. Additional surgeries performed in our study did 
Table 2 Types of hernia, symptomatology, surgeries performed, and their complications

\begin{tabular}{|c|c|c|c|c|c|}
\hline S. No. & $\begin{array}{l}\text { Types of } \\
\text { hernia }\end{array}$ & $n=816$ & Clinical features & Method of repair & $\begin{array}{l}\text { Complications } \\
n=66 \text { (8.0\% of patients) }\end{array}$ \\
\hline 1. & $\begin{array}{l}\text { Direct } \\
\text { inguinal } \\
\text { hernia }\end{array}$ & $\begin{array}{l}n=349 \\
(42.8 \%)\end{array}$ & $\begin{array}{l}\text { Elderly } \\
\text { Reducible inguinal swelling }\end{array}$ & $\begin{array}{l}\text { Lap-Hernioplasty } \\
\text { Lichtenstein's repair }\end{array}$ & \multirow{9}{*}{$\begin{array}{l}\text { 1. Hematoma/seroma } \\
10(1.2 \%) \\
\text { 2. Wound infection and } \\
\text { dehiscence } \\
20(2.4 \%) \\
\text { 3. Scrotal Hematoma } \\
6(0.7 \%) \\
\text { 4. Mesh extrusion/ removal } \\
2(0.24 \%) \\
\text { 5. Nerve entrapment \& pain } \\
20(2.4 \%) \\
\text { 6. Recurrence } \\
6(0.73 \%) \\
\text { 7. Mortality } \\
2(0.24 \%)\end{array}$} \\
\hline 2. & $\begin{array}{l}\text { Indirect } \\
\text { inguinal } \\
\text { hernia }\end{array}$ & $\begin{array}{l}n=252 \\
(30.9 \%)\end{array}$ & $\begin{array}{l}\text { Children, young adults }>\text { elderly } \\
\text { Reducible/partially reducible } \\
\text { irreducible } \\
\text { Pain }\end{array}$ & $\begin{array}{l}\text { Bassini's repair } \\
\text { Lichtenstein's repair } \\
\text { Lap hernioplasty }\end{array}$ & \\
\hline 3. & $\begin{array}{l}\text { Femoral } \\
\text { hernia }\end{array}$ & $\begin{array}{l}n=4 \\
(0.4 \%)\end{array}$ & $\begin{array}{l}\text { Irreducible } \\
\text { Pain } \\
\text { Obstructed }\end{array}$ & $\begin{array}{l}\text { Lotheissen's repair } \\
\text { Lap-hernioplasty }\end{array}$ & \\
\hline 4. & $\begin{array}{l}\text { Epigastric } \\
\text { hernia }\end{array}$ & $\begin{array}{l}n=33 \\
(4 \%)\end{array}$ & $\begin{array}{l}\text { Epigastric bulge } \\
\text { Irreducible/partially reducible } \\
\text { Pain }\end{array}$ & $\begin{array}{l}\text { Anatomical repair } \\
\text { Meshplasty }\end{array}$ & \\
\hline 5. & $\begin{array}{l}\text { Umbilical } \\
\text { hernia }\end{array}$ & $\begin{array}{l}n=25 \\
(3 \%)\end{array}$ & $\begin{array}{l}\text { Bulge } \\
\text { Reducible/irreducible } \\
\text { Obstructed }\end{array}$ & $\begin{array}{l}\text { Meshplasty } \\
\text { Mayo's repair }\end{array}$ & \\
\hline 6. & $\begin{array}{l}\text { Paraumbilical } \\
\text { hernia }\end{array}$ & $\begin{array}{l}n=16 \\
(2 \%)\end{array}$ & $\begin{array}{l}\text { Bulge } \\
\text { Irreducible/reducible }\end{array}$ & $\begin{array}{l}\text { Meshplasty } \\
\text { Mayo's repair }\end{array}$ & \\
\hline 7. & $\begin{array}{l}\text { Incisional } \\
\text { hernia }\end{array}$ & $\begin{array}{l}n=82 \\
(10 \%)\end{array}$ & $\begin{array}{l}\text { Previous surgery } \\
\text { Bulge } \\
\text { Reducible/partially reducible } \\
\text { Irreducible } \\
\text { Pain }\end{array}$ & $\begin{array}{l}\text { Meshplasty } \\
\text { Lap-hernioplasty }\end{array}$ & \\
\hline 8. & $\begin{array}{l}\text { Spigelian } \\
\text { hernia }\end{array}$ & $\begin{array}{l}n=3 \\
(0.35 \%)\end{array}$ & $\begin{array}{l}\text { Bulge } \\
\text { Reducible }\end{array}$ & Meshplasty & \\
\hline 9. & $\begin{array}{l}\text { Traumatic } \\
\text { hernia }\end{array}$ & $\begin{array}{l}n=5 \\
(0.65 \%)\end{array}$ & $\begin{array}{l}\text { Bulge } \\
\text { H/o trauma } \\
\text { Occasional pain }\end{array}$ & Meshplasty & \\
\hline
\end{tabular}

Table 3 Simultaneous surgeries performed

\begin{tabular}{|c|c|c|c|c|c|}
\hline S. No & $\begin{array}{l}\text { Simultaneous surgeries } \\
\text { performed }\end{array}$ & $\begin{array}{l}n=130 \\
(16.0 \%)\end{array}$ & $\%$ & Diagnosis & $\begin{array}{l}\text { Herniotomy/herniorrhaphy/ } \\
\text { hernioplasty } \\
\text { PLUS }\end{array}$ \\
\hline 1. & Hydrocele & 18 & 13.8 & Clinical/USG proven & Eversion of sac \\
\hline 2. & Undescended testis & 7 & 5.4 & Clinical/USG proven & Orchidopexy/orchidectomy \\
\hline 3. & Contralateral hernia & 30 & 23 & Examination findings & $\mathrm{B} / \mathrm{L}$ hernia repair \\
\hline 4. & Inguinal + other hernias & 17 & 13 & Examination findings & Hernioplasty/Mayo's repair \\
\hline 5. & Bladder outlet obstruction & 20 & 15.5 & $\begin{array}{l}\text { Urinary complaints } \\
\text { USG findings }\end{array}$ & TURP/OIU \\
\hline 6. & Hemorrhoids & 10 & 7.7 & $\begin{array}{l}\text { Bleeding } \mathrm{P} / \mathrm{R} \\
\text { Proctoscopy }\end{array}$ & Hemorrhoidectomy \\
\hline 7. & Bowel gangrene & 5 & 3.8 & $\mathrm{~S} / \mathrm{S}$ of strangulation & Resection and anastomosis \\
\hline 8. & Cholelithiasis & 5 & 3.8 & USG proven & Laparoscopic cholecystectomy \\
\hline 9. & Appendix in sac & 4 & 3.2 & Operative finding & Appendicectomy \\
\hline 10. & Gynecological procedures & 14 & 10.8 & $\begin{array}{l}\text { Planned gynecological } \\
\text { procedures }\end{array}$ & Gynecological surgeries \\
\hline
\end{tabular}

Abbreviations: OIU, optical internal urethrotomy; TURP, transurethral resection of the prostrate.

not add to either morbidity or mortality yet saved the patient the trauma of a second procedure, and we would recommend it unless it has a direct bearing on the healing process, like active infection and chances of contamination, which may then be contraindications to performing them simultaneously with a hernia repair.

\section{Conclusion}

Abdominal wall hernias are a common entity and account for approximately $10 \%$ of our total outpatient attendance. Most of the patients in our rural setting presented late, more than 2 years after developing the hernia and often with 
e46 Abdominal Wall Hernias Pandya et al.

complications. Proper health awareness, especially among the rural population and females, is what is important and is advocated. Mesh repair is the standard procedure applicable to most of the population. A laparoscopic hernioplasty is best suited to these population groups, as it results in a lesser hospital stay and early return to work. Laparoscopy has a longer learning curve however and hence requires to be customized as per the need of the population, and reduction in its financial implications could be beneficial.

\section{Conflicts of Interest}

None declared.

\section{References}

1 Dabbas N, Adams K, Pearson K, Royle G. Frequency of abdominal wall hernias: is classical teaching out of date? JRSM Short Rep 2011;2(01):5

2 Jenkins JT, O'Dwyer PJ. Inguinal hernias. BMJ 2008;336(7638):269-272
3 Rao S, Singh P, Gupta D, Narang R. Clinicoepidemiologic profile of inguinal hernia in rural medical college in central India. J Mahatma Gandhi Inst Med Sci 2016;21(02):116

4 van Wessem KJ, Simons MP, Plaisier PW, Lange JF. The etiology of indirect inguinal hernias: congenital and/or acquired? Hernia 2003;7(02):76-79

5 van Veen RN, van Wessem KJ, Halm JA, et al. Patent processus vaginalis in the adult as a risk factor for the occurrence of indirect inguinal hernia. Surg Endosc 2007;21(02):202-205

6 Ayandipo 00, Afuwape 0O, Irabor DO, Abdurrazzaaq AI. Adult abdominal wall hernia in ibadan. Ann Ib Postgrad Med 2015;13(02):94-99

7 Ohene-Yeboah M, Abantanga F, Oppong J, et al. Some aspects of the epidemiology of external hernias in Kumasi, Ghana. Hernia 2009;13(05):529-532

8 Mabula JB, Chalya PL. Surgical management of inguinal hernias at Bugando Medical Centre in northwestern Tanzania: our experiences in a resource-limited setting. BMC Res Notes 2012;5(01):585

9 HerniaSurge Group. International guidelines for groin hernia management. Hernia 2018;22(01):1-165

10 Burcharth J. The epidemiology and risk factors for recurrence after inguinal hernia surgery. Dan Med J 2014;61(05):B4846 